\title{
The malignancy among gastric submucosal tumor
}

\author{
Bin Yang, Xinliang Lu \\ Department of Gastroenterology, The Second Affiliated Hospital, Zhejiang University School of Medicine, Hangzhou 310009, China \\ Contributions: (I) Conception and design: All authors; (II) Administrative support: X Lu; (III) Provision of study materials or patients: All authors; (IV) \\ Collection and assembly of data: B Yang; (V) Data analysis and interpretation: B Yang; (VI) Manuscript writing: All authors; (VII) Final approval of \\ manuscript: All authors. \\ Correspondence to: Dr. Xinliang Lu. Department of Gastroenterology, The Second Affiliated Hospital, Zhejiang University School of Medicine, 88 \\ Jiefang Road, Hangzhou 310009, China. Email: lux@zju.edu.cn.
}

\begin{abstract}
The origin and characteristics of most submucosal tumors (SMTs) cannot easily be confirmed by gastrointestinal endoscopy or other radiological examinations. Excluding GISTs, for those other gastric SMTs, most of which are deemed benign, the necessity and timing of intervention has been ignored. Thus, the malignancy of gastric SMTs still remains unknown. In order to summarize the malignancy of these gastric SMTs, we reviewed literatures and analyzed cases of gastric SMTs including heterotopic pancreas, leiomyoma, schwannoma, glomus tumor, hemangioendothelioma, granular cell tumor (GCT), lipoma, hemangiopericytoma, lymphangioma and neurofibroma. In these literatures, there are cases of malignancy among heterotopic pancreas, leiomyoma, schwannoma, glomus tumor, hemangioendothelioma and GCT. As a result, it suggests that although most of gastric SMTs are considered benign, there are still possibilities of malignancy, which requires our attention, even active intervention and long-term follow-up.
\end{abstract}

Keywords: Gastric submucosal tumor (gastric SMT); malignancy

Submitted Jun 03, 2019. Accepted for publication Oct 10, 2019.

doi: $10.21037 /$ tcr.2019.10.41

View this article at: http://dx.doi.org/10.21037/tcr.2019.10.41

\section{Introduction}

The submucosal tumor (SMT), or subepithelial tumor (SET), is clinically common protuberant lesions or lumps covered with intact mucosa (1). The origin and characteristics of most SMTs cannot easily be confirmed by gastrointestinal endoscopy or other radiological examinations. These SMTs can be divided into mesenchymal tumors and non-tumorous submucosal lesions (2). And the mesenchymal tumors include benign, borderline malignant and malignant tumors (3). The majority of SMTs seldom cause symptoms, but are detected incidentally by endoscopic or radiologic examinations (4).

As is known to all, gastrointestinal stromal tumor (GIST) has been already widely studied. There are relatively reliable guidelines for the diagnosis and treatment of gastric GISTs in Western and Asian countries, such as the clinical guidelines of GISTs published by the National Comprehensive Cancer Network (NCCN) in 2004 (5), and by the European Society of Medical Oncology (ESMO) in 2014 (6). However, excluding GISTs, for those other gastric SMTs, most of which are deemed benign, the necessity and timing of intervention has been ignored.

For reference, this paper will focus on the malignancy of gastric SMTs which are generally considered benign.

\section{Heterotopic pancreas}

Heterotopic pancreas is defined as pancreatic tissue abnormally situated, which is anatomically characterized by the separation of pancreatic tissue from glands, without neurological or vascular continuity (7). The most common site of gastrointestinal heterotopic pancreas is the stomach (25-62\%), followed by the duodenum (25-35\%), and jejunum (16\%) (8). The clinical manifestations of heterotopic pancreas is asymptomatic or non-specific, such as epigastric pain, nausea, vomiting and so on. Therefore, it is usually detected by endoscopy examination or autopsy 
Table 1 Information of reviewed gastric submucosal tumors

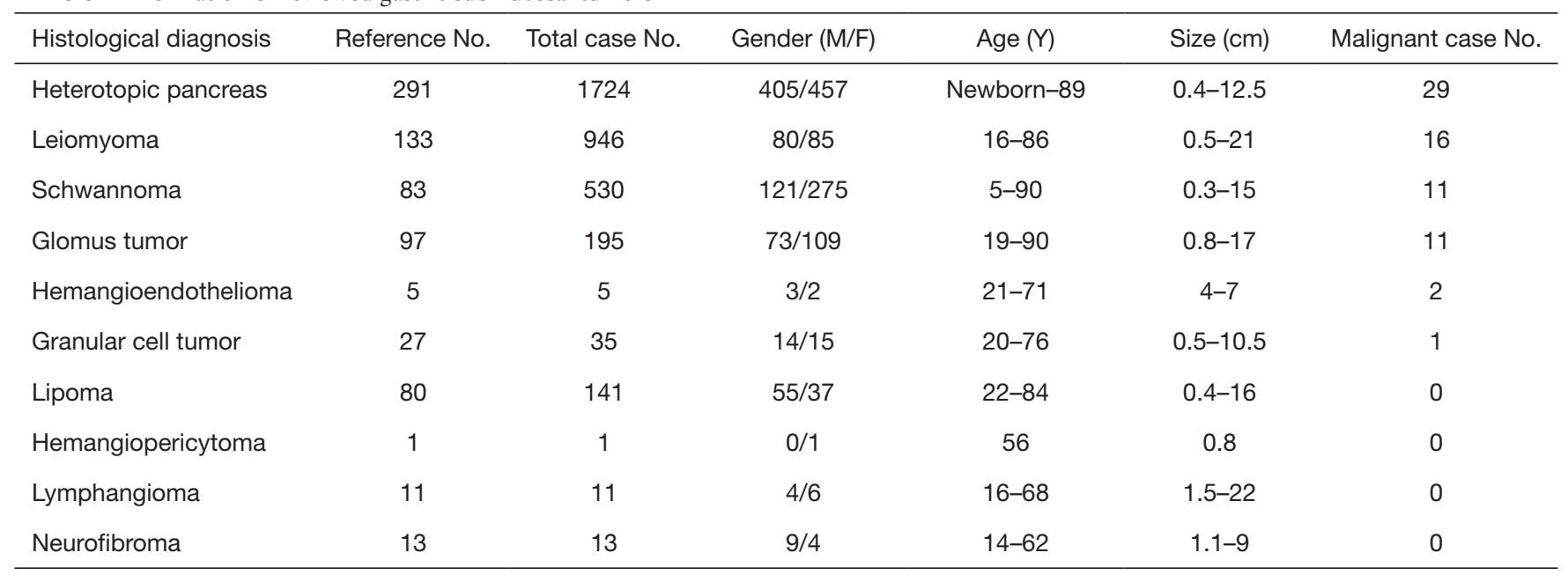

incidentally (9).

The malignant tumors of gastric heterotopic pancreas are comparatively rare but need to be alarmed. There were 1,724 cases reported in the literature, which were composed of newborn to 89 years old patients. The sex ratio $(\mathrm{M} / \mathrm{F})$ was about 0.9 . The tumor size ranged from 0.4 to $12.5 \mathrm{~cm}$. Of all the 1,724 cases reported from 1980 to 2018, we found 29 cases with malignant features (Table 1). For a carcinoma to be described as arising from heterotopic pancreatic tissue, three criteria have been proposed: (I) the tumor must be found within, or close to, the ectopic pancreatic tissue; (II) transition between pancreatic structures and carcinoma must be observed (i.e., duct-cell dysplasia and/or carcinoma in situ); (III) the non-neoplastic pancreatic tissue must include at least fully developed acini and duct structures. The lesion in this case met all three criteria (10). The 29 cases were confirmed pathologically originated from gastric heterotopic pancreas. Among the 29 malignant cases, most of them were adenocarcinoma (21/29), and other pathological types included papillary cystadenocarcinoma, mucinous cystadenocarcinoma, neuroendocrine carcinoma, acinar cell carcinoma and so on. Mean age of the cases was $58.4 \pm 15.6[27-86]$ years old and the male to female ratio was 14/15. The tumor size ranged from 1.7 to $12.5 \mathrm{~cm}$ (Table 2).

In addition to malignant cases of heterotopic pancreas, pancreatic intraepithelial neoplasia (PanIN) and intraductal papillary mucinous neoplasms (IPMN) have also been found in heterotopic pancreas. In 1,724 cases, 47 PanINs/ IPMNs were found. Based on the mathematical analysis by Yachida et al. (75), it takes about 12 years for PanIN-1 to transform into PanIN-3, which can cause pancreatic ductal adenocarcinomas. According to the study by Jun et al. (76), PanINs/IPMNs were more frequently found in heterotopic pancreas of large size, deep location and infiltrative growth pattern. And most PanINs/IPMNs associated with heterotopic pancreas were low-grade, so progression to ductal adenocarcinoma during a short follow-up period is unlikely.

Therefore, although the malignant cases are rare in gastric heterotopic pancreas, we also need to be cautious when we find gastric heterotopic pancreas.

\section{Leiomyoma}

Leiomyoma is the most common SMT of upper gastrointestinal tract (77). Until the 1980s, GIST was not significantly different from a leiomyoma. It was not until 1983 when Mazur and Clark (78) proposed the concept of stromal tumors that their differences were gradually noticed. And in 1998, Hirota et al. (79) confirmed the pathogenic effect of Kit (CD117) proto-oncogene activating mutation on GISTs. Subsequently, GISTs were confirmed to have the characteristics of Cajal interstitial cells, which more specifically differ leiomyoma from GIST. So in order to get more reliable data, we only searched literatures between 2008-2018.

From 2008 to 2018, we reviewed 133 literatures and found 946 cases of gastric leiomyoma reported. Of the 946 cases, 16 were leiomyosarcomas. The clinical manifestations of these malignant tumors were not specific, such as epigastric pain, melena, gastric outlet obstruction and so on. The average age of these 16 cases was $52.7 \pm 20.7$ 


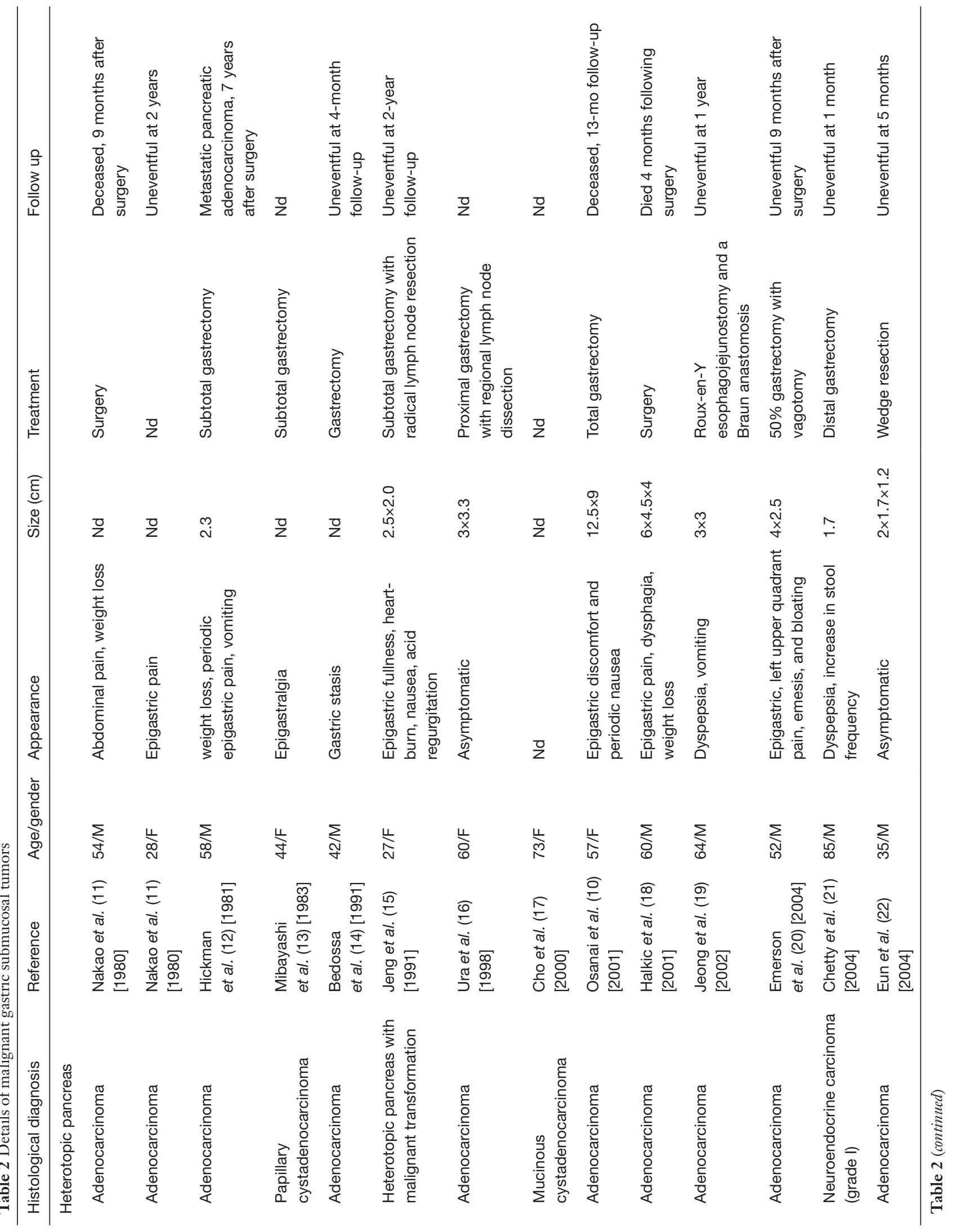




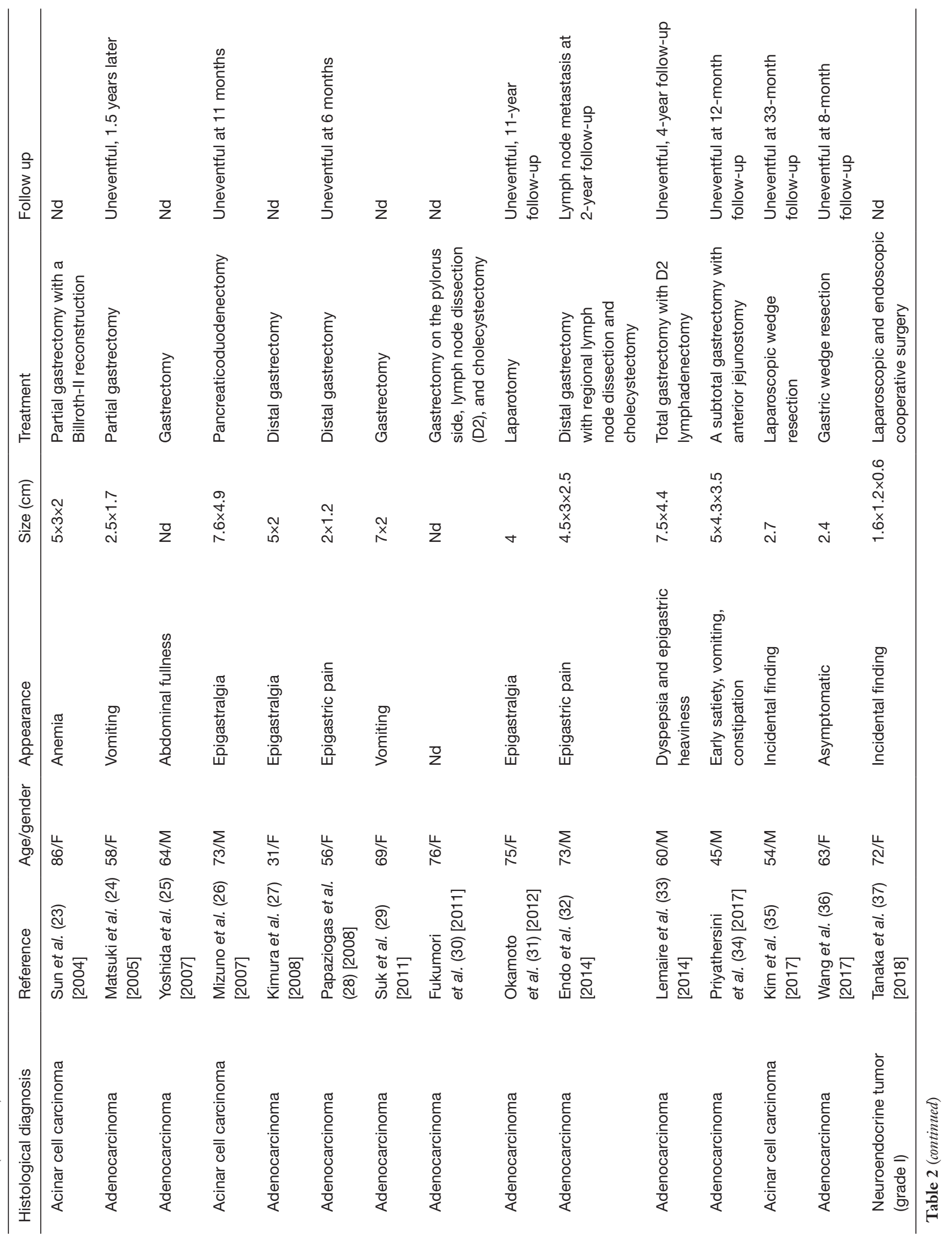




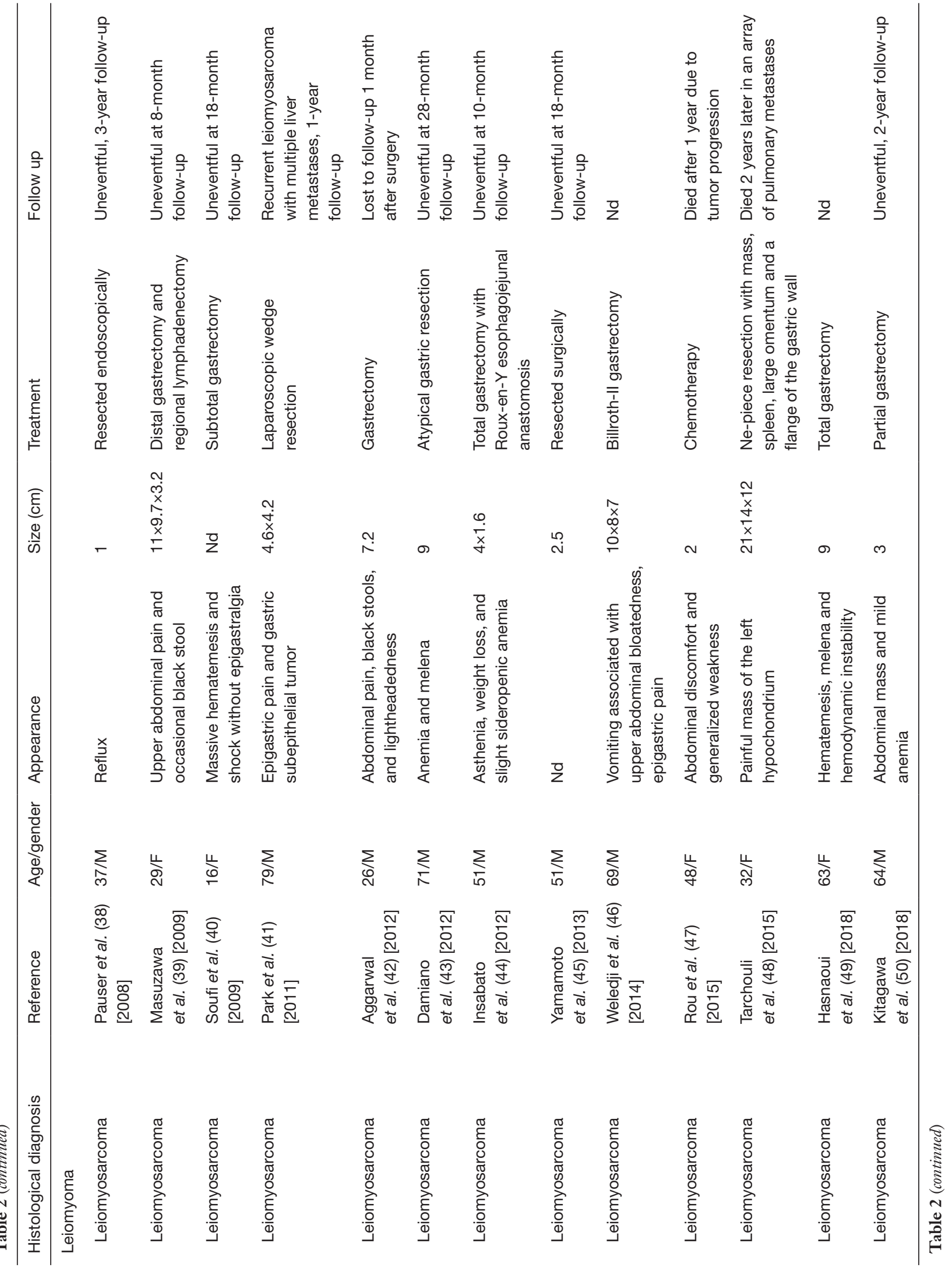




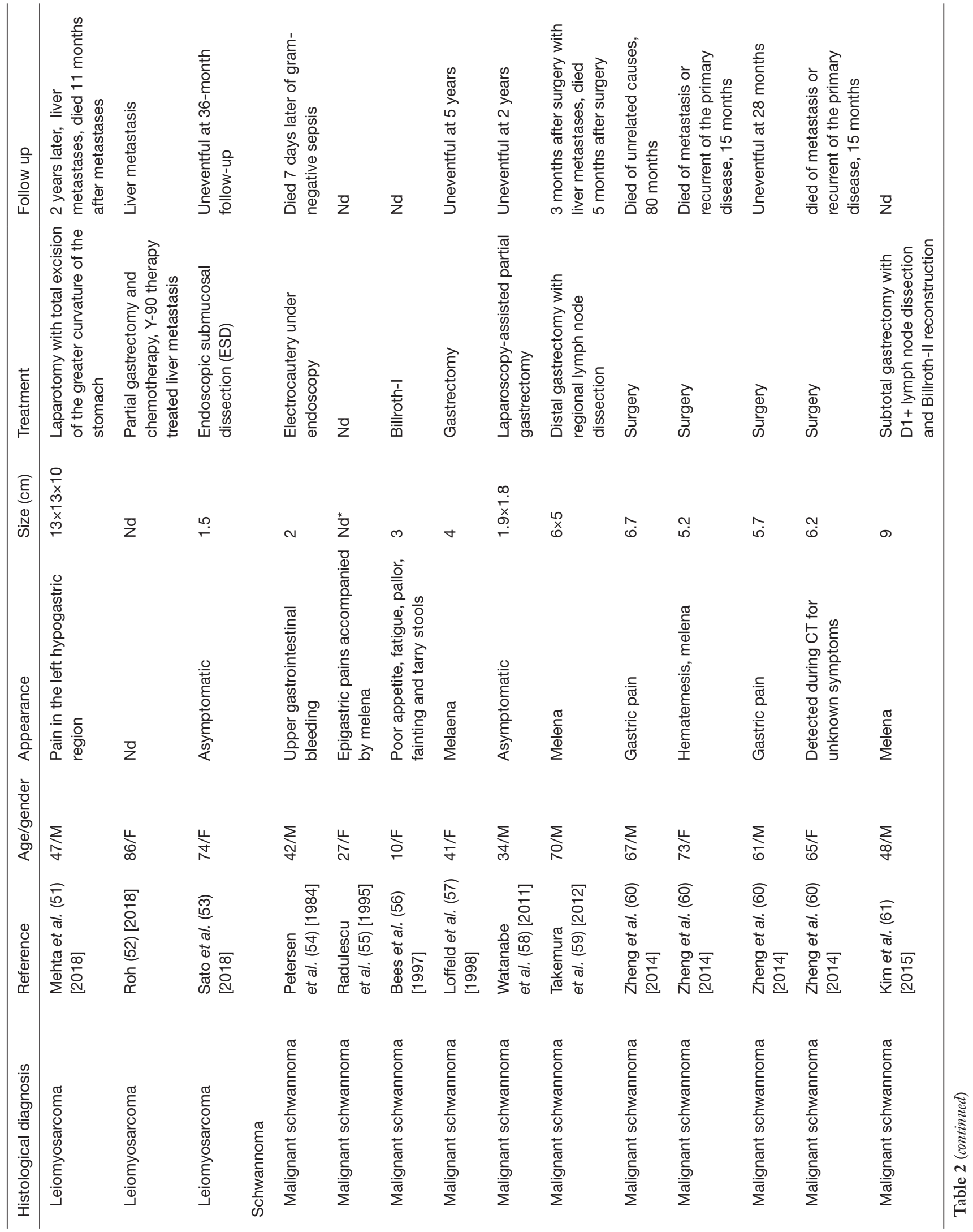




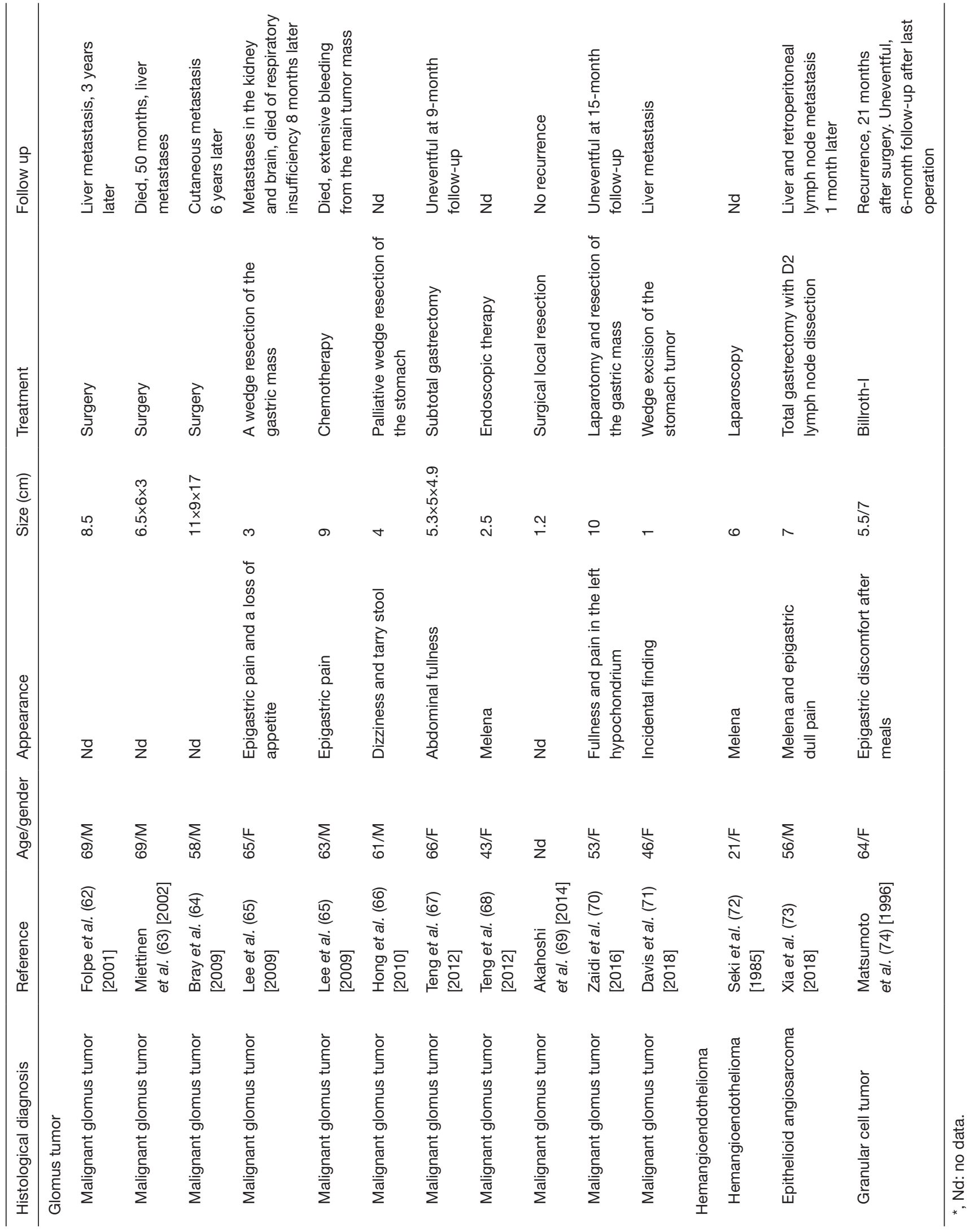


[16-86] years old. The male to female ratio was $9 / 7$. The average size of tumors was $7.06 \pm 5.60[1-21] \mathrm{cm}$. The literature indicates that gastric leiomyosarcomas often occurs in the elderly and are typically of high grade malignancy (38). However, our review showed that some middle-aged and even young patients also suffer from this disease. And the tumor size was also extensively ranged. So neither age nor tumor size can be used as criteria for judging malignant potential. Some leiomyosarcomas had distant metastases at initial diagnosed. And liver and lungs were the most common sites.

\section{Schwannoma}

Schwannomas of the GI tract, firstly presented by Daimaru et al. in 1988 (80), which are mostly benign tumors arising from the schwann cells of the nerve sheath. The most common site $(60-70 \%$ of all GI cases) is the stomach, followed by the colon and rectum (3\%). Small intestinal and esophageal schwannomas are rarely reported (81).

Malignant gastric schwannomas are extremely rare, with only a few cases reported (Table 1). Of all the 530 cases reviewed, 11 showed malignancy (Table 2). Based on these conditions, we may conclude that malignant gastric schwannoma has atypical appearance with common gastrointestinal symptoms. Among these cases, there were 6 males and 5 females. The mean age of these cases was $48.9 \pm 20.2[10-73]$ years old and the mean size of tumors was $4.97 \pm 2.25[1.9-9] \mathrm{cm}$. Although the data of all the 530 cases showed a female predominance, the sex ratio of malignant schwannoma was close to $1: 1$, even male patients accounted for the majority. So we speculate that the possibility of malignancy is more likely to occur in males. With the increase of malignant cases, gender preference may decrease, and we can more intuitively analyze the characteristics of malignant schwannoma.

\section{Vascular tumor}

Vascular tumors, including angiogenic tumors and lymphangiomas, are relatively rare. Angiogenic tumors include glomus tumor, hemangioendothelioma, hemangiopericytoma and so on.

Glomus tumor, which is composed of modified smooth muscle cells (82), is an arteriovenous anastomosis functioning without an intermediary capillary bed (83). Most glomus tumors are benign neoplasms that occur in the dermis or subcutis of the extremities (84). Glomus tumors of stomach are relatively rare and often lead to gastrointestinal bleeding due to ulceration of the mucosa over which it is covered (85). We reviewed 97 articles and 195 cases from 1980 to 2018. According to the literature, the ages ranged from 19 to 90 . Pathologically confirmed malignancy was found in 11 cases, and potential malignancy was uncertain in 3 cases. The others were benign. Folpe et al. (62) suggested malignant criteria of glomus tumors: tumors with a deep location and a size of more than $2 \mathrm{~cm}$, or atypical mitotic figures, or moderate to high nuclear grade and $\geq 5$ mitotic figures/50 HPF. All these 11 tumor cases met the above criteria. Of the 10 cases, 5 were male and 5 were female. The gender of the remaining 1 patient was not mentioned. The average age was 59.3 \pm 9.2 [43-69] years and the average tumor size was $6.18 \pm 4.75[1-17] \mathrm{cm}$. As mentioned above, we can conclude that malignant cases usually occur in elderly patients and the risk of distant metastases cannot be ignored. And there seems to be no correlation between tumor size and malignant potential. The clinical manifestations of malignant tumors are mostly gastrointestinal symptoms without specificity. Although malignancy is rare in glomus tumors, we still need to pay close attention to it. What's more, due to the risk of distant metastasis, long-term follow-up is necessary.

Hemangioendotheliomas which affects various parts of the digestive system (86) is classified into four types: Epithelioid hemangioendothelioma, spindle cell hemangioendothelioma, kaposiform hemangioendothelioma and endovascular papillary hemangioendothelioma (malignant tumor known as Dabska) (87). Gastric hemangioendotheliomas were rarely reported, only 5 cases, 2 of which were malignant tumors (Table 2). The tumor size of these 2 cases was relatively large. However, due to the limited number of cases, we cannot summarize the reliable common features of their malignancies.

Hemangiopericytoma of the stomach is even rarer and we found only one benign case of gastric lipomatous hemangiopericytoma. Lipomatous hemangiopericytoma is a variant of hemangiopericytoma, which is histologically composed of benign hemangiopericytomatous and mature lipomatous components (88). This was the first case of lipomatous hemangiopericytoma that occurred in the stomach, and more data is needed to deduce the possibility of malignancy.

Lymphangiomas are relatively rare compared with hemangiomas. And the digestive tract is rarely involved (89). We found 11 cases of gastric lymphangiomas, none of which were malignant. 


\section{Granular cell tumor (GCT)}

GCT, first described by Abrikosoff in 1926 (90), is a benign mesenchymal tumor originating from schwann cell (91). GCTs most commonly affect the tongue, skin and subcutaneous tissue. And, $5 \%$ to $11 \%$ of GCTs are found in the gastrointestinal tract, and they mostly affect the esophagus, colon, or stomach (92). According to Fanburg-smith, there are six histologic criteria: necrosis, spindling, vesicular nuclei with large nucleoli, increased mitotic activity ( $>2$ mitoses/10 high-power fields at 200x magnification), high nuclear to cytoplasmic (N:C) ratio, and pleomorphism. Neoplasms that met three or more of these criteria were classified as histologically malignant; those that met one or two criteria were classified as atypical; and those that displayed only focal pleomorphism but fulfilled none of the other criteria were classified as benign (93).

From January $1^{\text {st }}, 1980$ to December $31^{\text {st }}, 2018$, we found 36 cases of gastric GCTs (Table 1). Some of these gastric GCTs may coexist with gastric carcinoma and early gastric cancer. However, the pathology of these GCTs was confirmed benign. There was only one case of malignant gastric GCT, which was reported in 1996 by Matsumoto et al. A 64-year-old female was referred to the hospital for treatment due to upper abdominal discomfort after eating and gastroscopic evidence of enlargement of a SMT which had been managed conservatively by the hospital since 5 years ago. This neoplasm consisted of two tumor masses, 5.5 and $7.0 \mathrm{~cm}$ in diameter, respectively, which were connected to form a dumbbell-shaped lesion. After distal partial gastrectomy, reconstruction was performed by Billroth-I Method. The pathology of this case met the following criteria mentioned above: increased mitotic activity and pleomorphism. Although it only met two of the criteria, 21 months after the operation, the tumor recurred along the inferior border of the liver, $10.5 \mathrm{~cm} \times 7.5 \mathrm{~cm} \times$ $7.5 \mathrm{~cm}$. Pathological characteristics of the tumor were similar to those of the primary tumor. Thus, considering the clinical and pathological evidence of local recurrence, the neoplasm was considered malignant (74).

\section{Lipoma}

Gastric lipomas account for less than $1 \%$ of gastric tumors and $5 \%$ of gastrointestinal lipomas (94). Lipomas are completely benign, although there is a risk of local recurrence, less than $5 \%$ (95). Of the 141 cases reviewed, no malignancy was reported (Table 1).

\section{Neurofibroma}

Neurofibroma often occurs in neurofibromatosis and solitary neurofibromas are rare (96). Neurofibromatosis type 1 is more common, frequently involving gastrointestinal tract (97). We reviewed 13 cases of gastric neurofibroma and none of them had malignant features. However, the clinical manifestations of neurofibromatosis are various, ranging from localized microscopic proliferative lesions of autonomic nerves and interstitial cells of Cajal and diffuse microscopic ganglio/neuro/fibromatosis to grossly recognizable mass-forming neurofibromas and GIST (98). Therefore, when gastric neurofibroma is diagnosed, neurofibromatosis needs to be considered and be alert.

\section{Conclusions}

We reviewed literatures and analyzed cases of gastric SMTs including GCT, lipoma, schwannoma, heterotopic pancreas, leiomyoma, vascular tumor (glomus tumor, hemangioendothelioma, hemangiopericytoma, lymphangioma) and neurofibroma. In this literature, there are cases of malignancy among GCT, schwannoma, heterotopic pancreas, leiomyoma, glomus tumor and hemangioendothelioma. It suggests that although most of these gastric SMTs are considered benign, there are still possibilities of malignancy, which requires our attention, even active intervention and long-term follow-up.

\section{Acknowledgments}

Funding: Zhejiang Provincial Natural Science Foundation of China, LY17H160022.

\section{Footnote}

Conflicts of Interest: All authors have completed the ICMJE uniform disclosure form (available at http://dx.doi. org/10.21037/tcr.2019.10.41). The authors have no conflicts of interest to declare.

Ethical Statement: The authors are accountable for all aspects of the work in ensuring that questions related to the accuracy or integrity of any part of the work are appropriately investigated and resolved.

Open Access Statement: This is an Open Access article distributed in accordance with the Creative Commons Attribution-NonCommercial-NoDerivs 4.0 International 
License (CC BY-NC-ND 4.0), which permits the noncommercial replication and distribution of the article with the strict proviso that no changes or edits are made and the original work is properly cited (including links to both the formal publication through the relevant DOI and the license). See: https://creativecommons.org/licenses/by-nc-nd/4.0/.

\section{References}

1. Wiech T, Walch A, Werner M. Histopathological classification of nonneoplastic and neoplastic gastrointestinal submucosal lesions. Endoscopy 2005;37:630-4.

2. Oh JY, Nam KJ, Choi JC, et al. Benign submucosal lesions of the stomach and duodenum: Imaging characteristics with endoscopic and pathologic correlation. Eur J Radiol 2008;67:112-24.

3. Nishida T, Kawai N, Yamaguchi S, et al. Submucosal tumors: comprehensive guide for the diagnosis and therapy of gastrointestinal submucosal tumors. Dig Endosc 2013;25:479-89.

4. Chak A. EUS in submucosal tumors. Gastrointest Endosc 2002;56:S43-8.

5. Demetri GD, Benjamin R, Blanke CD, et al. NCCN Task Force report: optimal management of patients with gastrointestinal stromal tumor (GIST)--expansion and update of NCCN clinical practice guidelines. J Natl Compr Canc Netw 2004;2 Suppl 1:S-1-26; quiz 7-30.

6. ESMO/European Sarcoma Network Working Group. Gastrointestinal stromal tumours: ESMO Clinical Practice Guidelines for diagnosis, treatment and follow-up. Ann Oncol 2014;25 Suppl 3:iii21-6.

7. Sheshe AA, Yusuf I. Ectopic Pancreas Causing Partial Gastric Outlet Obstruction: A Case Report and Review of Literature. Niger J Surg 2018;24:56-9.

8. Stock C, Keutgen XM, Pisapia D, et al. Heterotopic pancreatic neoplasm presenting as an obstructing mass at the fourth portion of the duodenum. JOP 2011;12:241-3.

9. Wei R, Wang QB, Chen QH, et al. Upper gastrointestinal tract heterotopic pancreas: findings from CT and endoscopic imaging with histopathologic correlation. Clin Imaging 2011;35:353-9.

10. Osanai M, Miyokawa N, Tamaki T, et al. Adenocarcinoma arising in gastric heterotopic pancreas: clinicopathological and immunohistochemical study with genetic analysis of a case. Pathol Int 2001;51:549-54.

11. Nakao T, Yanoh K, Itoh A. Aberrant pancreas in Japan. Review of the literature and report of 12 surgical cases.
Med J Osaka Univ 1980;30:57-63.

12. Hickman DM, Frey CF, Carson JW. Adenocarcinoma arising in gastric heterotopic pancreas. West J Med 1981;135:57-62.

13. Mibayashi Y. Carcinoma originating from the heterotopic pancreas in the stomach a case. Stomach \& Intestine (Tokyo) 1983:267-72.

14. Bedossa P, Millat B, Zrihen E, et al. Adenocarcinoma in heterotopic gastric pancreas. Gastroenterol Clin Biol 1991;15:79-82.

15. Jeng KS, Yang KC, Kuo SH. Malignant degeneration of heterotopic pancreas. Gastrointest Endosc 1991;37:196-8.

16. Ura H, Denno R, Hirata K, et al. Carcinoma arising from ectopic pancreas in the stomach: endosonographic detection of malignant change. J Clin Ultrasound 1998;26:265-8.

17. Cho JS, Shin KS, Kwon ST, et al. Heterotopic pancreas in the stomach: CT findings. Radiology 2000;217:139-44.

18. Halkic N, Nordback P. Soft-tissue images. Malignant degeneration of heterotopic pancreas. Can J Surg 2001;44:407.

19. Jeong HY, Yang HW, Seo SW, et al. Adenocarcinoma arising from an ectopic pancreas in the stomach. Endoscopy 2002;34:1014-7.

20. Emerson L, Layfield LJ, Rohr LR, et al. Adenocarcinoma arising in association with gastric heterotopic pancreas: A case report and review of the literature. J Surg Oncol 2004;87:53-7.

21. Chetty R, Weinreb I. Gastric neuroendocrine carcinoma arising from heterotopic pancreatic tissue. J Clin Pathol 2004;57:314-7.

22. Song DE, Kwon Y, Kim KR, et al. Adenocarcinoma Arising in Gastric Heterotopic Pancreas: A Case Report. J Korean Med Sci 2004;19:145-8.

23. Sun Y, Wasserman PG. Acinar cell carcinoma arising in the stomach: A case report with literature review. Hum Pathol 2004;35:263-5.

24. Matsuki M, Gouda Y, Ando T, et al. Adenocarcinoma arising from aberrant pancreas in the stomach. J Gastroenterol 2005;40:652-6.

25. Yoshida T, Umemoto A, Yamai H, et al. A case of adenocarcinoma arising from the gastric ectopic pancreas. Jpn J Gastroenterol Surg 2007;40:1576-81.

26. Mizuno Y, Sumi Y, Nachi S, et al. Acinar cell carcinoma arising from an ectopic pancreas. Surg Today 2007;37:704-7.

27. Kimura J, Kaji M, Yamamoto SI, et al. A case of adenocarcinoma arising from ectopic gastric pancreas 
with carcinomatous peritonitis. Jpn J Gastroenterol Surg 2008;41:399-405.

28. Papaziogas B, Koutelidakis I, Tsiaousis P, et al. Carcinoma developing in ectopic pancreatic tissue in the stomach: a case report. Cases J 2008;1:249.

29. Suk H, Hang L, Seung S, et al. A Case of Gastric Adenocarcinoma Arising from Ectopic Pancreas showing Gastric Outlet Obstruction. Clinical Endoscopy 2011;42:373-7.

30. Fukumori D, Matsuhisa T, Taguchi K, et al. Ectopic gastric pancreatic cancer: report of a case. Hepatogastroenterology 2011;58:740-4.

31. Okamoto H, Kawaoi A, Ogawara T, et al. Invasive ductal carcinoma arising from an ectopic pancreas in the gastric wall: a long-term survival case. Case Rep Oncol 2012;5:69-73.

32. Endo S, Saito R, Ochi D, et al. Effectiveness of an Endoscopic Biopsy Procedure Using EUS-FNA and EMR-C for Diagnosing Adenocarcinoma Arising from Ectopic Pancreas: Two Case Reports and a Literature Review. Intern Med 2014;53:1055-62.

33. Lemaire J, Delaunoit T, Molle G. Adenocarcinoma arising in gastric heterotopic pancreas. Case report and review of the literature. Acta Chir Belg 2014;114:79-81.

34. Priyathersini N, Sundaram S, Senger JL, et al. Malignant Transformation in Gastric Pancreatic Heterotopia A Case Report and Review of the Literature. JOP 2017;18:73-7.

35. Kim KM, Kim CY, Hong SM, et al. A primary pure pancreatic-type acinar cell carcinoma of the stomach: a case report. Diagn Pathol 2017;12:10.

36. Wang C, Huang R, Li Z, et al. Clinicopathological characteristics of tumor-like lesions arising in gastric heterotopic pancreas. Int J Clin Exp Pathol 2017;10:6528-35.

37. Tanaka T, Omote R, Okazaki N, et al. Gastric neuroendocrine tumor arising from heterotopic pancreas. Clin J Gastroenterol 2018;11:34-7.

38. Pauser U, Grimm H. Intramucosal leiomyosarcoma of the stomach following hereditary retinoblastoma in childhood - a case report and review of the literature. World J Surg Oncol 2008;6:131.

39. Masuzawa N, Kishimoto M, Nishimura A, et al. Gastric leiomyosarcoma manifesting peculiar findings: radiological-pathological correlation. Pathol Int 2009;59:306-11.

40. Soufi M, Errougani A, Chekkof RM. Primary gastric leiomyosarcoma in young revealed by a massive hematemesis. J Gastrointest Cancer 2009;40:69-72.
41. Park SY, Lee CK, Park JS, et al. A Case of Multiple Liver Metastasis of True Gastric Leiomyosarcoma after Complete Surgical Resection. Soonchunhyang Med Sci 2011;17:138-42.

42. Aggarwal G, Sharma S, Zheng M, et al. Primary leiomyosarcomas of the gastrointestinal tract in the postgastrointestinal stromal tumor era. Ann Diagn Pathol 2012;16:532-40.

43. Damiano G, Di Ganci S, Palumbo VD, et al. Gastric leiomyosarcoma: case report and review of literature. Clinica Terapeutica 2012;163:e181-4.

44. Insabato L, Masone S, Campione S, et al. Coexistence of primary gastric giant cell-rich leiomyosarcoma and gastrointestinal stromal tumor: report of a very rare combination and review of the literature. Int J Surg Pathol 2012;20:74-8.

45. Yamamoto H, Handa M, Tobo T, et al. Clinicopathological features of primary leiomyosarcoma of the gastrointestinal tract following recognition of gastrointestinal stromal tumours. Histopathology 2013;63:194-207.

46. Weledji EP, Enoworock G, Ngowe MN. Gastric leiomyosarcoma as a rare cause of gastric outlet obstruction and perforation: a case report. BMC Res Notes 2014;7:479.

47. Rou WS, Ju JS, Kang SH, et al. A case of gastric leiomyosarcoma with multiple metastases. Korean J Gastroenterol 2015;65:112-7.

48. Tarchouli M, Bounaim A, Brahim Ratbi M, et al. Gastric leiomyosarcoma simulating splenic hilum tumor: report of a case. Pan African Medical Journal 2015;21:263.

49. Hasnaoui A, Jouini R, Haddad D, et al. Gastric leiomyosarcoma and diagnostic pitfalls: a case report. BMC Surg 2018;18:62.

50. Kitagawa H, Kaneko M, Kano M, et al. Coexistence of gastrointestinal stromal tumor and leiomyosarcoma of the stomach presenting as a collision tumor: A case report and review of literature. Pathol Int 2018;68:313-7.

51. Mehta V, Rajawat M, Rastogi S, et al. Leiomyosarcoma of the stomach with metastasis to the liver: a case report with review of the literature. Future Sci OA 2017;4:FSO264.

52. Roh S. Radiation segmentectomy for gastric leiomyosarcoma hepatic metastasis. Korean J Clin Oncol 2018;14:142-5.

53. Sato T, Akahoshi K, Tomoeda N, et al. Leiomyosarcoma of the stomach treated by endoscopic submucosal dissection. Clin J Gastroenterol 2018;11:291-6.

54. Petersen JM, Ferguson DR. Gastrointestinal neurofibromatosis. J Clin Gastroenterol 1984;6:529-34. 
55. Rădulescu D, Stoian M, Sarbu M. Gastric malignant schwannoma. Rev Med Chir Soc Med Nat Iasi 1995;99:221-5.

56. Bees NR, DicksMireaux C, Kiely EM. Gastric malignant schwannoma in a child. Br J Radiol 1997;70:952-5.

57. Loffeld RJ, Balk TG, Oomen JLT, et al. Upper gastrointestinal bleeding due to a malignant Schwannoma of the stomach. Eur J Gastroenterol Hepatol 1998;10:159-62.

58. Watanabe A, Ojima H, Suzuki S, et al. An individual with gastric schwannoma with pathologically malignant potential surviving two years after laparoscopy-assisted partial gastrectomy. Case Rep Gastroenterol 2011;5:502-7.

59. Takemura M, Yoshida K, Takii M, et al. Gastric malignant schwannoma presenting with upper gastrointestinal bleeding: a case report. J Med Case Rep 2012;6:37.

60. Zheng L, Wu X, Kreis ME, et al. Clinicopathological and Immunohistochemical Characterisation of Gastric Schwannomas in 29 Cases. Gastroenterol Res Pract 2014;2014:202960.

61. Kim EY, Lee SH, Yoo HM, et al. Gastric Malignant Peripheral Nerve Sheath Tumor: A Case Report. Int J Surg Pathol 2015;23:505-8.

62. Folpe AL, Fanburg-Smith JC, Miettinen M, et al. Atypical and malignant glomus tumors: analysis of 52 cases, with a proposal for the reclassification of glomus tumors. Am J Surg Pathol 2001;25:1-12.

63. Miettinen M, Paal E, Lasota J, et al. Gastrointestinal glomus tumors: a clinicopathologic, immunohistochemical, and molecular genetic study of 32 cases. Am J Surg Pathol 2002;26:301-11.

64. Bray AP, Wong NA, Narayan S. Cutaneous metastasis from gastric glomus tumour. Clin Exp Dermatol 2009;34:e719-21.

65. Lee H, Choi YS, Oh SC, et al. Malignant Glomus Tumors of the Stomach - A Report of 2 Cases with Multiple Metastases. Korean J Pathol 2009;43:358-63.

66. Hong SR, Hong HS, Noh S. A Bleeding Gastric Tumor With Concurrent Hypervascular Hepatic Nodules Malignant Glomus Tumor of the Stomach With Multiple Hepatic Metastases. Gastroenterology 2010;139:1466-798.

67. Teng TH, Huang SH, Liang CW. Malignant gastric glomus tumour mimicking GIST. Pathology 2012;44:261-3.

68. Teng L, Ke C, Yan M, et al. Atypical glomus tumor of the body of stomach: a case report and review of literature. The Chinese-German Journal of Clinical Oncology 2012;11:668-71.
69. Akahoshi K, Oya M, Koga T, et al. Clinical usefulness of endoscopic ultrasound-guided fine needle aspiration for gastric subepithelial lesions smaller than $2 \mathrm{~cm}$. J Gastrointestin Liver Dis 2014;23:405-12.

70. Zaidi S, Arafah M. Malignant Gastric Glomus Tumor: A Case Report and Literature Review of a Rare Entity. Oman Med J 2016;31:60-4.

71. Davis J, Petterson M, Newell J, et al. Micrometastatic gastric glomus tumour confirmed by next-generation sequencing. Histopathology 2018;72:351-4.

72. Seki K, Inui Y, Kariya Y, et al. A case of malignant hemangioendothelioma of the stomach. Endoscopy 1985;17:78-80.

73. Xia J, Shi D, Wu Z, et al. The poor prognosis of the primary gastric epithelioid angiosarcoma: A case report. Medicine (Baltimore) 2018;97:e0287.

74. Matsumoto H, Kojima Y, Inoue T, et al. A malignant granular cell tumor of the stomach: report of a case. Surg Today 1996;26:119-22.

75. Yachida S, Jones S, Bozic I, et al. Distant metastasis occurs late during the genetic evolution of pancreatic cancer. Nature 2010;467:1114-7.

76. Jun SY, Son D, Kim MJ, et al. Heterotopic Pancreas of the Gastrointestinal Tract and Associated Precursor and Cancerous Lesions Systematic Pathologic Studies of 165 Cases. Am J Surg Pathol 2017;41:833-48.

77. Ozdil B, Akkiz H, Kece C, et al. Endoscopic alcohol injection therapy of giant gastric leiomyomas: an alternative method to surgery. Can J Gastroenterol 2010;24:533-5.

78. Mazur MT, Clark HB. Gastric stromal tumors. Reappraisal of histogenesis. Am J Surg Pathol 1983;7:507-19.

79. Hirota S, Isozaki K, Moriyama Y, et al. Gain-of-function mutations of c-kit in human gastrointestinal stromal tumors. Science 1998;279:577-80.

80. Daimaru Y, Kido H, Hashimoto H, et al. Benign schwannoma of the gastrointestinal tract: a clinicopathologic and immunohistochemical study. Hum Pathol 1988;19:257-64.

81. Mekras A, Krenn V, Perrakis A, et al. Gastrointestinal schwannomas: a rare but important differential diagnosis of mesenchymal tumors of gastrointestinal tract. BMC Surg 2018;18:47.

82. Tsuneyoshi M, Enjoji M. Glomus tumor: a clinicopathologic and electron microscopic study. Cancer 1982;50:1601-7.

83. Xu XD, Lu XH, Ye GX, et al. Immunohistochemical analysis and biological behaviour of gastric glomus 
tumours: a case report and review of the literature. J Int Med Res 2010;38:1539-46.

84. Lee HW, Lee JJ, Yang DH, et al. A clinicopathologic study of glomus tumor of the stomach. J Clin Gastroenterol 2006;40:717-20.

85. Kim JK, Won JH, Cho YK, et al. Glomus tumor of the stomach: CT findings. Abdom Imaging 2001;26:303-5.

86. Tavares AB, Almeida AG, Viveiros FA, et al. Gastric epithelioid haemangioendothelioma. BMJ Case Rep 2011. doi: 10.1136/bcr.01.2011.3791.

87. Weiss SW, Enzinger FM. Epithelioid hemangioendothelioma: a vascular tumor often mistaken for a carcinoma. Cancer 1982;50:970-81.

88. Nielsen GP, Dickersin GR, Provenzal JM, et al. Lipomatous hemangiopericytoma. A histologic, ultrastructural and immunohistochemical study of a unique variant of hemangiopericytoma. Am J Surg Pathol 1995;19:748-56.

89. Yamaguchi K, Maeda S, Kitamura K. Lymphangioma of the stomach - report of a case and review of the literature. Jpn J Surg 1989;19:485-8.

90. Jain A, Karegar M, Joshi A, et al. Granular Cell Tumour in Stomach: a Case Report. Indian J Surg Oncol 2018;9:598-600.

91. An S, Jang J, Min K, et al. Granular cell tumor of the gastrointestinal tract: histologic and immunohistochemical

Cite this article as: Yang B, Lu X. The malignancy among gastric submucosal tumor. Transl Cancer Res 2019;8(7):2654-2666. doi: $10.21037 /$ tcr.2019.10.41 analysis of 98 cases. Hum Pathol 2015;46:813-9.

92. Barakat M, Kar AA, Pourshahid S, et al. Gastrointestinal and biliary granular cell tumor: diagnosis and management. Ann Gastroenterol 2018;31:439-47.

93. Fanburg-Smith JC, Meis-Kindblom JM, Fante R, et al. Malignant granular cell tumor of soft tissue: diagnostic criteria and clinicopathologic correlation. Am J Surg Pathol 1998;22:779-94.

94. Ingason AB, Theodors A, Agustsson AS, et al. Giant gastric lipoma successfully removed by endoscopic submucosal dissection: case report and systematic review. Scand J Gastroenterol 2018;53:1018-24.

95. Amundson JR, Straus D, Azab B, et al. Giant symptomatic gastric lipoma: A case report and literature review. Int J Surg Case Rep 2018;51:313-7.

96. Day DW, Jass JR, Price AB, et al. Morson and Dawson's Gastrointestinal Pathology. J Clin Pathol 2003;56:399.

97. Ponsaing LG, Kiss K, Loft A, et al. Diagnostic procedures for submucosal tumors in the gastrointestinal tract. World J Gastroenterol 2007;13:3301-10.

98. Agaimy A, Vassos N, Croner RS. Gastrointestinal manifestations of neurofibromatosis type 1 (Recklinghausen's disease): clinicopathological spectrum with pathogenetic considerations. Int J Clin Exp Pathol 2012;5:852-62. 